ISSN 0258-7122 (Print), 2408-8293 (Online)

Bangladesh J. Agril. Res. 42(2): 309-319, June 2017

\title{
ABUNDANCE OF ARTHROPOD INSECT PESTS AND NATURAL ENEMIES IN RICE FIELD AS INFLUENCED BY RICE GROWTH STAGES AND NEIGHBORING CROPS
}

\author{
P. MUKHERJEE ${ }^{1}$ AND M. M. H. KHAN ${ }^{2}$
}

\begin{abstract}
Studies were conducted to record the abundance of arthropod insect pests and natural enemies in rice fields as influenced by rice growth stages and neighboring crops at the experimental farm of Patuakhali Science and Technology University (PSTU), Dumki, Patuakhali during 2012 in Boro rice season following randomized complete block design. Results indicated that ricetree habitat showed the highest abundance of leafhoppers (100.75) followed by cricket (16.50), grasshoppers (15.25) and stink bugs (15.25). The lowest abundance of all insect pests was in rice-sesame habitat. No significant differences were found on the abundance of rice bug, rice hispa and stem borer populations. At seedling stage, the highest abundance of leafhopper (94.25) was recorded followed by grasshopper (47.00) and stink bug (26.50) while the lowest was stem borer (0.57) and rice hispa (6.00). At early tillering stage, maximum number of grasshopper (17.25) was recorded followed by cricket (7.00). At maximum tillering stage, the highest abundance of leafhoppers (122.5) was obtained followed by rice bug (62.00) and the lowest was the stink bug (7.00). At panical initiation stage, the highest abundance of rice bug (334.00) was recorded which was followed by leafhoppers (65.25) and the lowest was the cricket (15.75). No population of rice hispa and stem borer was recorded at maximum tillering and panical initiation stages. In case of natural enemies, the highest abundance of lady bird beetle (45.27) and damselfly (16.73) was found in rice-rice habitat. The highest abundance of ichneumonid wasp (57.53) was in rice-tree habitat and ground beetle (28.80) was in ricesesame habitat. No significant differences were observed on the abundance of dragonfly, spider and dipteran fly among different habitats. Among different growth stages of rice plant, significantly the highest abundance of lady bird beetle was recorded at maximum tillering stage. The highest abundance of ichneumonid wasp and ground beetle was recorded at seedling stage. The highest abundance of damselfly, spider and dipteran fly was at early tillering stage. No significant difference was observed on the abundance of dragonfly among different rice growth stages.
\end{abstract}

Keywords: Abundance, insect pest, natural enemies, neighbouring crop, rice growth stage.

\footnotetext{
${ }^{1-2}$ Department of Entomology, Patuakhali Science and Technology University, Dumki, Patuakhali, Bangladesh.
} 


\section{Introduction}

Bangladesh is an agricultural country and its agriculture is predominantly rice based. The average yield of rice in Bangladesh is quite low which is $3.02 \mathrm{t} \mathrm{ha}^{-1}$ (BBS, 2014) compared to other rice growing countries like China $\left(6.23 \mathrm{t} \mathrm{ha}^{-1}\right)$, Korea $\left(6.59 \mathrm{t} \mathrm{ha}^{-1}\right)$, Japan $\left(6.79 \mathrm{t} \mathrm{ha}^{-1}\right)$ and USA producing $\left(7.04 \mathrm{t} \mathrm{ha}^{-1}\right)$, respectively (FAO, 2004). The majority of rice growing area of Bangladesh is covered by boro rice comprising $58 \%$ of the total rice area. Rice is grown round the year in Bangladesh. So, this crop is an ideal host for many insect pest species. So far, 175 species of insects have been identified on rice from seed sowing to crop harvest (Kamal, 1998). Among them, only 20 species are considered as pest (Pathak, 1968) and 20-30 species are economically important (Miah and Karim, 1984). All of the fauna present in rice fields are not harmful. Many of them are beneficial. These beneficial fauna categorized as predators and parasitoids collectively known as natural biological enemies. In most of the cases, these enemies are able to interact with their prey or host populations and regulate them at economically lower level.

Arthropods in the rice ecosystem vary widely depending on the distribution of rice and other crops and wild habitats. The dynamics of pests and natural enemies in the area is influenced by the crop management. Xiaoping et al. (1995) reported that the size and composition of non-rice habitats adjacent to rice fields may have positive roles on natural enemies in rice fields. As the population development of some species in rice fields seems to be related to non-rice habitats adjacent to rice fields (Chiu, 1979), undoubtedly the biodiversity of fauna and flora exerts an important role in integrated pest management of rice (Way and Heong, 1994). However, relatively little work has been conducted on the understanding how neighboring crops affect pest biology and ecology. There is a need for rice IPM tailored to complex farming systems. Considering the above facts, the present study was undertaken to assess the abundance of insect pests and these natural enemies in rice fields as influenced by rice growth stage and neighbouring crops.

\section{Materials and Method}

The studies were conducted to record the abundance of arthropod insect pests and natural enemies in rice fields as influenced by rice growth stages and neighboring crops at the experimental farm of Patuakhali Science and Technology University (PSTU), Dumki, Patuakhali during the period from January to June 2012 in Boro rice following randomized complete block design (RCBD) with four replications. The rice variety, BRRIdhan 29 was used for the study. A variety of non-rice crops viz., sesame and maize were grown widely along with rice as a neighbouring crops. To study the effect of different adjacent crop habitats on the abundance of rice arthropod population in rice fields, 4 types of rice fields were selected. These were: (a) rice field adjacent to sesame field designated as rice- 
sesame habitat, (b) rice field adjacent to maize field designated as rice-maize habitat, (c) rice field adjacent to trees designated as rice-tree habitat and (d) rice field adjacent to rice field designated as rice-rice habitat. Crop production procedure and other intercultural operations were done. No pesticide was used in the experimental fields.

\section{Data collection}

The insect pests of rice and their natural enemies were collected by a fine mesh nylon sweep net. Sweeping was done from the plant canopy level including the interspaces between plants and close to basal region of the plants as far as possible. In each field, 10 complete sweeps were made to collect the insect pests and their natural enemies. Sampling was done at four stages of rice viz. at seedling, early tillering, maximum tillering and panicle initiation stages. Sampling was done during morning hours at all study fields on all sampling dates.

The insect pests and nafural enemies of 10 complete sweeps from each field were collected separately in labeled container. The samples were sorted, counted and identified in the laboratory of the Department of Entomology, PSTU under microscope.

\section{Statistical analysis}

The data collected on different parameters used in the experiment were statistically analyzed to obtain the level of significance using the MSTAT-C computer package programme developed by Russell (1986). The analysis of variance (ANOVA) of the results on various insect pests and natural enemies was done after square root transformation $(\mathrm{y}=\sqrt{\mathrm{x}})$. The means were compared by Duncan's Multiple Range Test (DMRT).

\section{Results and Discussion}

The abundance of insect pests and natural enemies in rice field influenced by rice growth stage and neighbouring crops are presented in Table 1-4.

\section{Abundance of arthropod insect pests}

\section{Grasshopper}

Grasshopper population differed significantly within the four rice habitats (Table 1). Rice-tree habitat exhibited the highest population of grasshopper (15.25) which was statistically similar with rice-rice (15.00) habitats followed by ricemaize habitat (12.34). The rice-sesame habitat carried the lowest population (8.78). In case of different growth stages, the highest abundance of grasshopper was found at seedling stage (47.00) and the lowest abundance was recorded at 
early tillering stage (17.25) which was statistically similar with other two stages (Table 2).

\section{Rice bug}

Rice bug population did not varied significantly $(\mathrm{P}<0.05)$ within different rice habitats (Table 1). The mean number of rice bug ranged from 11.38 to 14.75. Rice-tree habitat showed the highest rice bug population (14.75) followed by rice-rice habitat (12.25) and the lowest abundance was found in rice-sesame habitat (11.38). On the other hand, significant difference was found on the rice bug population at different rice growth stages (Table 2). The highest rice bug population was found at panicle initiation stage (334.00) followed by maximum tillering stage (62.00) and the lowest was found at early tillering stage (0.75). No rice bug population was observed at seedling stage.

\section{Stink bug}

Stink bug population differed significantly $(\mathrm{P}<0.05)$ among different rice habitats with the means ranged from 8.56 to 15.25 (Table 1 ). The abundance of stink bug population was recorded in rice-tree habitat (15.25) which was statistically similar with rice-rice habitat (15.00). The lowest abundance was found in ricesesame habitat (8.56) which was statistically similar with rice-maize habitat (9.75). In case of different growth stages, significant differences of stink bug population was found (Table 2). The highest abundance was found at seedling stage (26.50) followed by panicle initiation stage (18.25) and the lowest abundance was found at maximum tillering stage. No stink bug population was observed at early tillering stage.

\section{Leafhopper}

Among different habitats, leafhopper population differed significantly $(\mathrm{p}<0.05)$ with the means ranged from 53.00 to 100.75 . The highest abundance was recorded in rice-tree habitat (100.75) followed by rice-rice habitat (76.00). Ricemaize and rice-sesame showed statistically similar abundance and exhibited the lowest population of 56.00 and 53.00, respectively (Table 1). In case of different growth stages, leafhopper also differed significantly (Table 2). The highest abundance was found at maximum tillering stage (122.50) which was statistically similar with that of seedling stage followed by panicle initiation stage and the lowest (3.75) at early tillering stage.

\section{Cricket}

Significant difference of cricket population was found in different rice habitats (Table 1). The highest abundance was found in rice-rice habitat (21.00 crickets/40 sweeps) followed by rice-tree habitat (16.50) and the lowest 
abundance was found in rice-maize habitat (9.00) which was statistically similar with rice-sesame habitat (10.00). In case of different rice growth stages, the highest abundance of cricket was found at maximum tillering stage (20.50 crickets/40 sweeps) followed by panicle initiation stage (15.75) which was statistically similar with seedling stage (13.25) (Table 2). The lowest abundance of cricket was found at early tillering stage ( 7.00 crickets/40 sweeps).

\section{Rice hispa}

No significant differences were found on the abundance of rice hispa population among the four rice habitats indicating all the habitats gave similar support to the rice hispa population (Tables 1). The highest population was observed in ricemaize ( 2.75 rice hispa/40 sweeps) habitat while the lowest was found in ricesesame (0.00 hispa/40 sweeps). In case of different growth stages, seedling stage carried the highest population of rice hispa (6.00 hispa/40 sweeps). The abundance of rice hispa population in other three stages were statistically similar (Table 2).

\section{Rice yellow stem borer}

No significant variation was found on the abundance of yellow stem borer (YSB) population among the four rice habitats indicating all the rice habitats gave similar support to the YSB population (Tables 1). The highest abundance was found in rice-sesame habitat (1.25) followed by rice-maize (1.00), and the lowest abundance of YSB was found in rice-rice habitat which was identical to rice-tree habitat (0.50). Similarly, among different growth stages, early tillering stage showed the highest abundance of YSB (1.62) followed by seedling (0.57) and there was no stem borer population in maximum tillering and panicle initiation stage (Table 2).

\section{Abundance of arthropod natural enemies}

\section{Ladybird beetle}

There was significant $(\mathrm{P}<0.05)$ differences in the lady bird beetle (LBB) population among rice habitats (Table 3 ). The highest population of LBB was observed in rice-rice habitat (45.27 LBB /40 sweeps) followed by rice-tree habitat. The lowest population of LBB was found in rice-maize habitat $(21.75$ $\mathrm{LBB} / 40$ sweeps) which was statistically similar with rice-sesame habitat (26.25). In case of different rice growth stages, LBB showed significant differences where the highest population was found in maximum tillering stage $(46.00 \mathrm{LBB} / 40$ sweeps) followed by panicle initiation and seedling stage, and the lowest population was found at early tillering stage $(6.50 \mathrm{LBB} / \mathrm{sweeps})$ (Table 4$)$. 

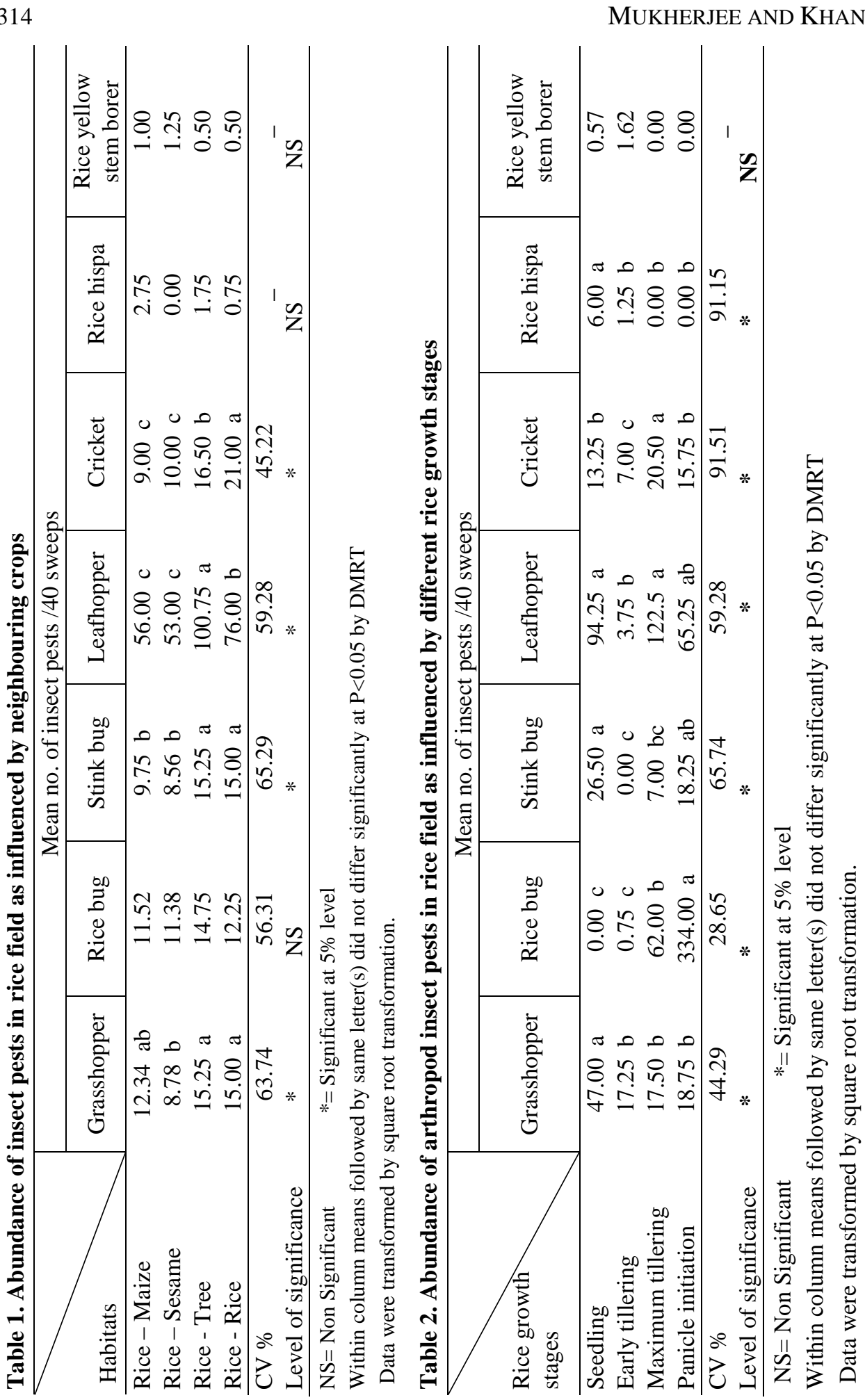


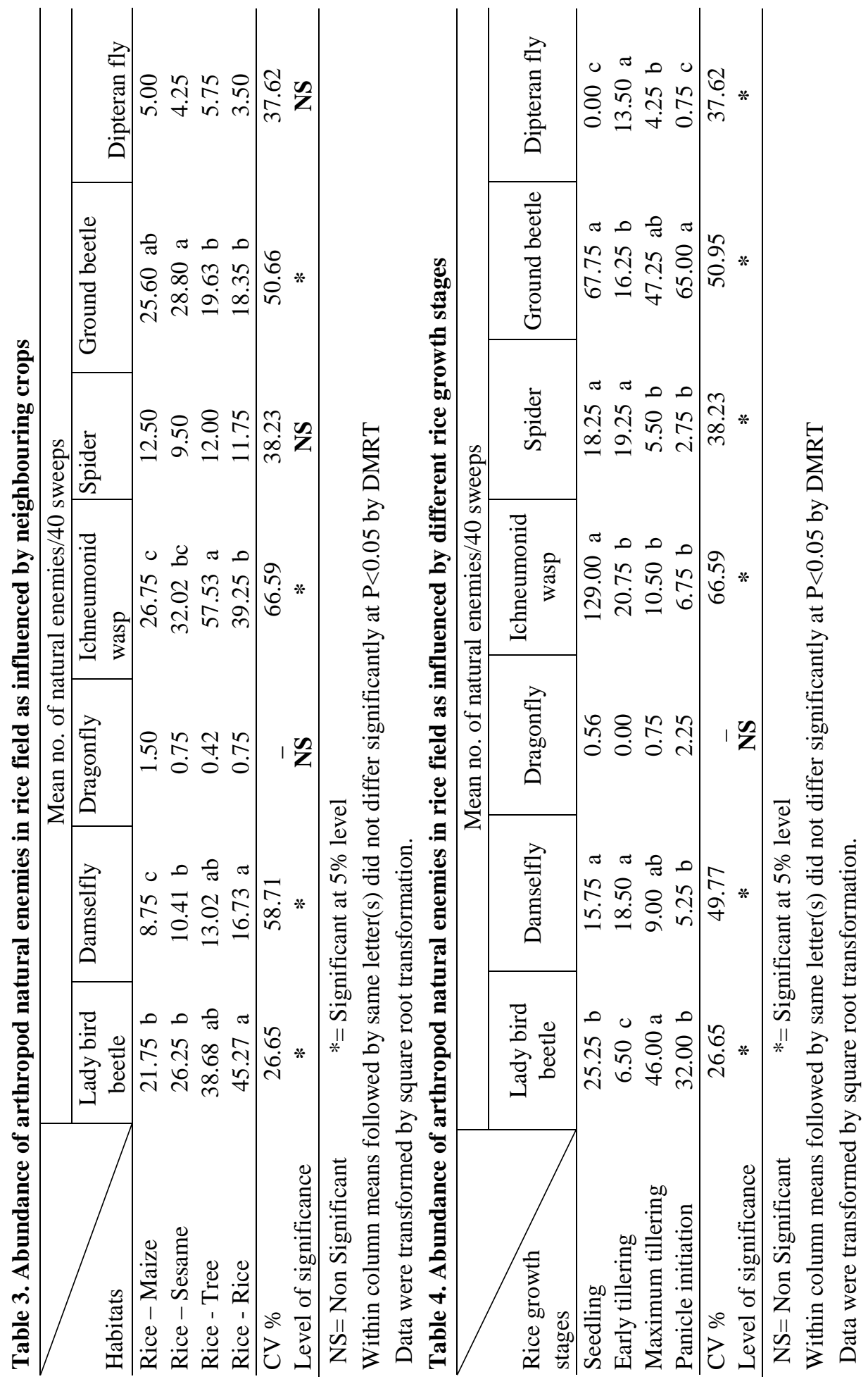




\section{Damselfly}

Damselfly population varied significantly $(\mathrm{P}<0.05)$ among different habitats with the means ranged from 8.75 to 16.73 (Table 3). Rice-rice habitat carried the highest population of damselfly (16.73) while the lowest abundance (8.75) was found in rice-maize habitat. In case of different growth stages, the highest population of damselfly (18.50) was found at early tillering stage which was statistically similar with seedling stages (15.75). The lowest abundance of damselfly was found at panicle initiation stage (5.25 damselfly/40 sweeps) followed by maximum tillering stage (9.00) (Table 4).

\section{Dragonfly}

Dragonfly population did not differ significantly within rice habitats. The maximum number of dragonfly was observed in rice-maize habitat (1.50 dragonfly/40 sweeps) followed by rice-sesame and rice-maize habitats. The minimum number of dragonfly was observed in rice-tree habitat $(0.42$ dragonfly/40 sweeps) (Table 3). In case of different growth stages, dragonfly population also did not differ significantly (Table 4). The highest abundance was at panicle initiation stage (2.25 dragonfly/40 sweeps) and the lowest was found at seedling stage. No dragonfly population was observed at early tillering stage.

\section{Ichneumonid wasp}

Ichneumonid wasp population differed significantly $(\mathrm{P}<0.05)$ among rice habitats with the means ranged from 26.75 to 57.53 (Table 3 ). Rice-tree habitat carried the highest ichneumonid wasp population (57.53) followed by rice-rice habitat (39.25). The lowest population was found in rice-maize habitat (26.75) followed by rice-sesame habitat. In case of different rice growth stages, seedling stage carried the highest population (129.0) and the lowest population was found at panicle initiation stage (6.75) which was statistically similar with maximum and early tillering stages (Table 4).

\section{Spider}

No significant variation of spider population was found among different habitats. The highest abundance was found in rice-maize habitat (12.50 spider/40 sweeps) followed by rice-tree habitats and the lowest abundance was found in rice-sesame habitat (9.50) followed by rice-rice habitat (Table 3). Spider population varied significantly $(\mathrm{P}<0.05)$ among different rice growth stages. The highest population was found at early tillering stage (19.25 spider/40 sweeps) which was statistically similar with seedling stage and the lowest population was found at maximum tillering stage (5.50) which was statistically similar with panicle initiation stage (Table 4). 


\section{Ground beetle}

Significant difference $(\mathrm{P}<0.05)$ of ground beetle $(\mathrm{GB})$ population was found among different habitats (Table 3). The highest abundance was found in ricesesame habitat $(28.80 \mathrm{~GB} / 40$ sweeps) followed by rice-maize habitat and the lowest abundance was found in rice-rice habitat (18.35) which was statistically similar with rice-tree habitat (19.63). Among different rice growth stages, significant difference was also found (Table 4). The highest population of GB was found at seedling stage $(67.75 \mathrm{~GB} / 40$ sweeps) which was statistically similar with panicle initiation stage (65.00) and the lowest population was found at early tillering stage (16.25) followed by maximum tillering stage (47.25).

\section{Dipteran fly}

No significant difference of dipteran fly population was found among different habitats (Table 3). The highest population was found in rice-tree habitat (5.75 flies/40 sweeps) followed by rice-maize habitat (5.00) and the lowest population was found in rice-rice habitat (3.50 flies/40 sweeps). In case of different growth stages, dipteran fly population showed significant difference (Table 4). The highest population was found at early tillering stage (13.50 flies/40 sweeps) followed by maximum tillering stage ( 4.25 flies/40 sweeps) and the lowest population was found at panicle initiation stage. No dipteran fly was observed at seedling stage.

Several studies indicated that increased habitat diversity in crops leads to increased population densities of indigenous predators and other arthropods and this enhanced biological control. Conglong (1995) intercropped sugarcane with sorghum and maize and this increased the population density of indigenous predators and arthropods in the intercrops as compared with pure stands of sugarcane. Elton (1958) reported that the abundance of arthropod insect pest population was more in monoculture habitat where polyculture habitat contains the lower abundance. Liu et al. (2001) studied population changes of major insect pests, natural enemies, and detritivores in rice habitats through habitat diversity. They found that soybean neighboring paddy fields was a beneficial habitat for conserving natural enemies of insect pests of rice without sharing the insect pest species with the rice habitat. Cheng et al. (1998) studied the role of non-rice habitats in predator conservation and found that non-rice habitats provided habitats for the development of predator population.

In case of different rice growth stages, the present study indicated that the abundance of most of the insect pests is high at panicle initiation stage where rice yellow stem borer population is highest at early tillering stage which is supported by Ragini et al. (2000) who found that yellow stem borer population was predominant at early tillering to maximum tillering stage. In present study, the 
highest rice bug population was found at panicle initiation stage and this result was agreed with Tsueda et al. (2002) who showed the ricebug abundance was peak at heading to early ripening stage. Some leaf feeders like grasshopper, rice hispa population showed the highest abundance at seedling stage which was agreed with the result of BRRI (1985) but the result of rice hispa population of this study was not supported by Amit et al. (2001) who found the abundance of rice hispa population was the highest at the mid tillering stage. The abundance of leafhopper population was the highest at maximum tillering stage which was more or less similar with the result of BRRI (1985) where highest leafhopper population was found at early heading stage. Among different rice growth stages, the present study showed that the abundance of natural enemies was the highest at seedling stage where spider population was the highest at early tillering stage which supported by Luong (1987) who studied the population was highest at tillering stage. In case of ladybird beetle (Micraspis spp) the highest population was found at maximum tillering stage which was more or less similar with the result of Rahman et al. (1991) who found that Lady bird beetle, Micraspis discolor was the highest at the flowering stage. Wang et al. (2001) investigated on dynamics of spatial distribution of mixed spider populations in early season rice fields and late season rice fields. They found that the spatial distribution of mixed spider populations in rice fields was different at different developmental stages of paddy rice. The main factors influencing spider spatial distribution in rice fields were spider dispersal level and reproduction, the number of netweaving spiders and wandering spiders, the number of main target pests and their distribution, variations of habitats and farming practices, density of spider populations and extent of inter-specific competition in rice fields.

\section{References}

Amit, C., Indira, D, Sharma, P.K., Kaul, B.K., Choudhary, A. and Dogra, I. 2001. Population build up of rice hispa. Dicladispa armigera armigera Oliv. (Coleoptera: Chrysomelidae) in Kangra valley of Himachal Pradesh (India). J. Entomol. Res. 25(4): 299-302.

BBS. 2014. Staistical Pocket Book Bangladesh, Bangladesh Bureau of Statistics. Statistics Division, Ministry of Planning, Government of the People's Republic of Bangladesh, Dhaka. Pp. 384.

BRRI, 1985. Annual Report for 1984. Bangladesh Rice Research Institute, Gazipur, 207p.

Cheng, J.A.; Lou, Y.G., Hamid, A.A., Yeang, L.K. and Sadi, T. 1998. Integrated science and people in rice pest management: proceedings of the Rice Integrated Pest Management (IPM) Conference, Kualalampur, Malaysia, 18-21 November 1996. 64-68p.

Chiu, S.C. 1979. Biological control of the brown planthopper. In: Brown plant hopper: threat to rice production in Asia. Manila (Philippines): Internat. Rice Res. Inst. Pp.335-355. 
Conglong, D.E. 1995. Results of preliminary pitfall trapping trials for potential arthropod predators of Eldana saccharina. Proc. South African Sug. Technologies Assoc. 69: 79-82.

Elton, C.S. 1958. The Ecology of Invasions by Animals and Plants. 181p. London, Chapman and Hall.

FAO. 2004. Production Yearbook. Food and Agriculture Organization of the United Nations. Rome, Italy. 57:76-77.

Kamal, N.Q. 1998. Brown Plant Hopper (BPH), Nilaparvata lugens Stal. Situation in Bangladesh. A report of IPM ecology expert. DAE-UNDP/FAO IPM project. Khamarbari, Farmgate, Dhaka, Bangladesh.

Liu, G., Lu, Z., Tang,J., Shen, J.; Jiang,Y., Sheng, X., Yang, B., Chen, J., and.Xu, H. 2001. Managing insect pests of temperate japonica rice by conserving natural enemies through habitat diversity and reducing insecticide use. Exploiting Biodiversity for Sustainable Pest Management. IRRI, 43-50 p.

Luong, M.C. 1987. Predators of brown plant hopper Nilaparvata lugens Stal (BPH) in rice fields of the Mekong Delta, Vietnam. Internat. Rice Res. Newslet. 12(2): 31- 32.

Miah, S.A. and Karim, A.N.M.R. 1984. Rice pest management technology, In: Proc. Workshop on Experience with modern rice cultivation in Bangladesh, BRRI. Gazipur. Pp. 43-49.

Pathak, M.D. 1968. Ecology of common insect pests of rice. Annual Review of Ent. 13:257-294.

Ragini, J.C., Thangaraju, D. and David, P.M.M. 2000. Relative abundance of rice stem borer species in Tamil Nadu. Madras Agril. Jour. Publ 2001 . S7(4-6): 228-234.

Rahman, M.H., Sardar, M.A. and Haque, M.R. 1991. Population dynamics of Micraspis discolor (Coccinellidae: Coleoptera) in rice and its susceptibility to insecticides. Bangladesh J. Ent. 1: 27-33.

Russell, D.F. 1986. MSTAT-C package programme. Crop and Soil Science Department, Michigan State University, USA.

Tsueda,,H., Yajima, M., Taguchi, Y. and Suzuki, T. 2002. Occurrence tendency of rice sting bugs in South, flat area of Gifu Prefecture. Proc. of the Kansai Plant Protection Soc. 4: 13-20.

Wang, Z., Yan, H.M, and Wang, H.Q. 2001. Studies on the dynamics of spatial distribution of mixed spider populations in rice fields. Plant Protection. 27(6): 9-11.

Way, M.J. and Heong, K.L. 1994. The role of diversity in the dynamics and management of insect pests of tropical irrigated rice: a review. Bull. Entomol. Res. 84: 567-587.

Xiaoping, Y., Heong, K.L., Cui, H. and Barrion, A.T. 1995. Role of non rice habitats for conserving egg parasitoids rice planthoppers and leafhoppers. In: Hokyo N, Norton G, editors. Proceeding of the International Workshop on Pest Management Strategies in Asian Monsoon Agroecosystem (Kumamoto 1995). 63-77p. 
